\title{
Cognition, Emotion and Fatigue Post-stroke
}

\author{
Caroline M. van Heugten and Barbara A. Wilson
}

\section{Introduction}

Stroke can have physical as well as cognitive, emotional and social consequences. Depending on the time of measurement, cognitive impairments are present in 50-70\% of stroke survivors (e.g. Rasquin et al. 2002, 2004; Nys et al. 2005; BarkerCollo and Feigin 2006). In the first 2 weeks almost every stroke patient (92\%) is impaired in at least one cognitive domain (Linden et al. 2005). Memory, executive functions, speed of information processing, language and visuo-spatial abilities are the most affected domains. The latter two have been discussed in chapters "Rehabilitation of Communication Disorders" and "Treating Neurovisual Deficits and Spatial Neglect", respectively.

Cognitive deficits have a negative impact on long-term outcomes such as independent functioning, community integration and quality of life (Nys et al. 2005; Duits et al. 2008; Van der Zwaluw et al. 2011; Barker-Collo et al. 2010; Wagle et al. 2011). Early identification of cognitive deficits is therefore necessary (van Dijk and de Leeuw 2012) and treatment should be offered accordingly (Langhorne et al. 2011; Albert and Kesselring 2012).

The same is true for emotional consequences after stroke. Depressive symptoms also have a profound influence on outcome and occur frequently. These symptoms range from 5 to $54 \%$ in the acute phase and remain present in 23-25\% after 6

C. M. van Heugten ( $ه)$

Brain Injury Center Limburg, Maastricht, The Netherlands

Department of Neuropsychology \& Psychopharmacology, Faculty of Psychology

\& Neuroscience, Maastricht University, Maastricht, The Netherlands

School for Mental Health and Neuroscience, Faculty of Health, Medicine and Life Sciences, Maastricht University Medical Center, Maastricht, The Netherlands

e-mail: caroline.vanheugten@maastrichtuniversity.nl

B. A. Wilson

The Oliver Zangwill Centre, Ely, UK 
months, when anxiety is present in 19-23\% (Whyte and Mulsant 2002; Aben et al. 2002; De Wit et al. 2008; Kouwenhoven et al. 2011). Prevalence rates decrease over time but after 2 years major depression is seen in $20 \%$ of the stroke patients (Van Mierlo et al. 2015). In research and clinical practice, more attention is paid to depression but anxiety is almost as common and the two symptoms often occur together. Irritability, agitation, eating disturbances and apathy are also commonly found post-stroke (Angelelli et al. 2004).

Another common and debilitating but also less visible problem after stroke is fatigue. A recent meta-analysis showed that prevalence estimates vary from 25 to $85 \%$ on the basis of the Fatigue Severity Scale with a pooled prevalence estimate of $50 \%$ (Cumming et al. 2016). Post-stroke fatigue is an independent predictor of disability and burden of care and should therefore be taken into account when formulating post-stroke rehabilitation treatment goals (Mandliya et al. 2016).

Patients usually receive further rehabilitation treatment after suffering a major stroke (Winstein et al. 2016), while full recovery is assumed in a transient ischemic attack (TIA), and minor stroke patients are discharged home without further rehabilitation or follow-up treatment (Edwards et al. 2006). However, previous studies in TIA and minor stroke patients found high prevalence of dysfunction across all domains of health, of which cognitive and emotional problems and fatigue were most notable (Arts et al. 2008; Muus et al. 2010; Radman et al. 2012; Moran et al. 2014) - and mostly specific to stroke (van der Kemp et al. 2017; De Graaf et al. 2018; Fens et al. 2013). These symptoms may be overlooked with conventional clinical measures such as the neurological examination or the Barthel Index, despite the fact that they can be a major contributor to an impaired performance in activities of daily living including decreased participation and a diminished quality of life (QOL) (Edwards et al. 2006; Duncan et al. 1997; Suenkeler et al. 2002; Verbraak et al. 2012).

\section{Best Evidence Synthesis}

Best evidence synthesis relevant to clinical decision-making (with reference to Cochrane reviews, meta-analyses and RCTs as well as selected guidelines) including (when applicable).

The evidence on therapy presented in this chapter is gathered by a systematic search in December 2017 using the following steps. First, the Cochrane database of systematic reviews was consulted to select the most recent reviews on cognition, emotion and fatigue post-stroke. In addition, the search terms from these reviews were used to find additional, more recent studies. In case no recent Cochrane review was available, PubMed was searched using the filter 'review' and a combination of the search terms 'stroke' and the topic of interest. Furthermore, studies were added on the basis of the authors' own knowledge of relevant studies in this field. The evidence on assessment is mostly based on the authors' own knowledge because Cochrane reviews are not available in this field. 


\subsection{Assessment: Brief Overview, Key Instruments}

\subsubsection{Screening for Cognitive Problems}

Given the high prevalence of cognitive and emotional consequences including fatigue after stroke and the negative impact on daily life functioning and social participation, it is important to screen every stroke patient for problems in these areas. Early screening can support the discharge destination and can help to plan the most adequate rehabilitation treatment and inform the patient and his or her caregivers about the possible consequences of these impairments in daily life and future functioning.

Cognitive screening early after stroke is recommended in many stroke guidelines and has even been determined as a key quality indicator of stroke services (Hachinski et al. 2006). Extensive neuropsychological assessment is recommended at later stages, but in the first days after stroke this is not feasible because patients may not be medically stable, can be fatigued easily and arousal levels may fluctuate. Screening for cognitive consequences should be conducted using a sensitive instrument specifically for stroke. From three systematic reviews in recent years (Stolwyk et al. 2014; Van Heugten et al. 2015; Burton and Tyson 2015), the Montreal Cognitive Assessment (MoCA) was identified as the most reliable, sensitive and feasible instrument for cognitive screening after stroke. A cutoff score of 26 is commonly used in stroke patients. In a recent study, it was shown that even in a mild stroke population $(n=324) 66.4 \%$ of the patients was cognitively impaired on the basis of the MoCA at 2 months post-stroke, with a significant improvement leaving 51.9\% impaired at 6 months (Nijsse et al. 2017b). All reviews on cognitive screening instruments state that the widely used Mini Mental State Examination (MMSE) should no longer be used for this purpose because it was originally designed for screening of dementia and is therefore not sufficiently sensitive for consequences of stroke. Also for TIA and mild stroke patient, the MoCA can be used (Sivakumar et al. 2014).

Cognitive impairment may arise due to damage to strategic areas of the brain, even in patients who do not have motor or communication deficits. Especially in the group of so-called 'walking and talking' patients (i.e. good outcome in terms of motor and communication functioning), cognitive problems may be missed (van Dijk and de Leeuw 2012; Mark 2012). A routine follow-up visit, which is often dedicated to secondary prevention, should therefore also include cognitive screening.

Additionally, people may experience subjective cognitive complaints which are not necessarily related to objective cognitive functioning. Subjective cognitive complaints are very common after stroke, may increase over time and have a negative impact on outcome (van Rijsbergen et al. 2014). The use of stroke-specific instruments that measure subjective cognitive complaints, such as the Checklist for Cognition and Emotion (CLCE-24; van Heugten et al. 2007), are preferred (van Rijsbergen et al. 2015). Patients and their informal caregivers may disagree about the presence, nature and severity of these problems (van Rijsbergen et al. 2014), which is why it is advisable to also ask the primary caregiver about potential 
problems in these areas. The CLCE-24 can also be used to assess the experience of cognitive changes by the patient's caregiver.

A 5-min cognitive screening such as the MoCA should be the absolute minimum, and cognitive assessment should only be restricted to this global form of initial assessment in the acute phase post-stroke and in later phases when no other means or capacity of neuropsychologists is available. The National Institute of Neurological Disorders and Stroke-Canadian Stroke Network Vascular Cognitive Impairment already proposed a 30-min and 60-min protocol for neuropsychological assessment as part of their harmonization standards (Hachinski et al. 2006). There may be cultural differences and therapist preferences for the use of specific instruments, but more extensive neuropsychological assessment in addition to a 5-min cognitive screening should be common practice after stroke. The choice for suitable neuropsychological instruments can be made by trained neuropsychologists; instruments specifically validated for stroke patients are preferred.

\subsubsection{Screening for Emotional Problems and Fatigue}

Screening for mood disorders should involve both depression and anxiety screening, and the Hospital Anxiety and Depression Scale (HADS) has been found to be the only available tool to accurately screen for both (Burton and Tyson 2015). A cutoff value of 7 for both subscales on depression (HADS-D) and anxiety (HADS-A) is commonly used. The Stroke Aphasic Depression Questionnaire-Hospital version (SADQ-H) has good psychometric properties and can also be used for stroke patients with aphasia (Burton and Tyson 2015; van Dijk et al. 2016).

The most widely used measure to screen for post-stroke fatigue is the Fatigue Severity Scale (FSS; Cumming et al. 2016). A cutoff value of 3 or 4 is commonly used. The FAS is also used after stroke. A cutoff of 24 provides the best sensitivity/ specificity values for the FAS (Cumming and Mead 2017).

\subsubsection{Further Neuropsychological Assessment}

Further neuropsychological assessment on cognitive, emotional, behavioural and social consequences should follow, especially when the screening has identified impaired functioning and also when there is a discrepancy between objective cognitive test results and subjective cognitive experiences by patients and caregivers. Neuropsychological rehabilitation or vocational rehabilitation should start with a thorough analysis of mental functions to assess both impaired and intact cognitive functions to identify strengths and weaknesses. Additionally, the impact of cognitive impairments on daily life functioning should be determined. Ideally, all levels of the framework of the International Classification of Functioning (ICF, WHO) are considered in a full neuropsychological assessment. In addition to assessment on the level of functions, activities and participation, the personal and external factors should be taken into account as well. In several studies, in the past few years, it has been shown that personal factors, especially psychological factors such as coping styles and personality traits influence the outcome after stroke (van Mierlo et al. 2014). In a large longitudinal cohort study on stroke patients we showed that more neuroticism, pessimism, passive coping and helplessness, and less extraversion, 
optimism, self-efficacy, acceptance, perceived benefits and proactive coping were associated with the presence of depressive symptoms at 2 months post-stroke (Van Mierlo et al. 2015). In the subsequent multivariate analyses, we showed that more helplessness and passive coping, and less acceptance and perceived benefits were independently significantly associated with the presence of depressive symptoms. Neuroticism at 2 months post-stroke appeared to be an independent predictor for both depression and anxiety at 1-year post-stroke in the same cohort (Kootker et al. 2016). Similarly, more proactive coping was related to less cognitive complaints at 2 months post-stroke (Nijsse et al. 2017a).

A treatment plan should be formulated at the start of rehabilitation allowing not only the planning of treatment but also the execution and evaluation. A stepwise approach is suggested by Wilson et al. (2003), which can be recommended to guide the treatment planning process. For an overview of all elements of a comprehensive neuropsychological assessment, we would like to refer to the chapter by Malec (2017) in the international handbook on neuropsychological rehabilitation (Wilson et al. 2017).

\subsection{Therapy (Training, Technology, Medication): This Is the Major Focus}

\subsubsection{Cognitive Rehabilitation}

After a stroke, spontaneous recovery can result in changes in structure and function of the brain, which is one form of neuroplasticity, but changes can also occur as a result of development, learning and environmental stimulation. Restoration of impaired cognitive functions will occur automatically to a certain extent but treatment is needed to further stimulate behavioural and brain changes. Restorative treatments are directed at the level of functions and have mostly short-term and only limited effects while long-lasting improvements in daily life functioning and societal participation should be the main goals of (neuro) rehabilitation.

Restorative approaches to cognitive rehabilitation are being investigated both in pre-clinical and clinical studies. In pre-clinical studies, cognitive enhancement approaches are tested in animal models such as enriched environment, early-onset multimodal stimulation, neuro-stimulating, pharmacotherapy or neuro-modulation (i.e. nervus vagus stimulation) but effects are small, mechanisms are not fully understood and generalization to humans is very difficult (e.g. Wogensen et al. 2015; Neren et al. 2016; Kochanek et al. 2015; Mala and Rasmussen 2017). One approach that raised renewed attention is the stimulation of cognitive functioning through physical exercise (i.e. multimodal stimulation). A recent meta-analysis showed that physical activity has small but significant positive effects on post-stroke cognition, even in the chronic phase (Oberlin et al. 2017). A total of 14 studies representing 736 participants showed an overall positive effect of physical activity on cognitive performance (Hedges' $g(95 \%$ confidence interval $)=0.30(0.14-0.47))$. Combined aerobic and strength training programs generated the largest effects. 
Improving the functionality of the whole brain in order to enhance the experiencedependent brain changes is the most probable explanation for these findings.

Clinical studies aimed at cognitive recovery focus on pharmacotherapy, computer-based cognitive retraining $(\mathrm{CBCR})$ and non-invasive brain stimulation (NIBS). Pharmacotherapy studies aimed at cognition functions in stroke patients are scarce, and a recent meta-analysis showed that there is insufficient evidence to evoke effects of central nervous system drugs on enhancing global cognition (Yeo et al. 2017). CBCR has become very popular in the last 10-15 years, both in clinical practice and among the public. The idea that cognitive functioning can be improved or decline can be prevented or even reversed by regularly playing computer games is attractive, but effects are limited to the trained tasks while near- and far-transfer effects to untrained tasks and daily life functioning are small or lacking (van Heugten et al. 2016; van Heugten 2017). The number of studies on NIBS is growing rapidly, and new techniques are being developed. A recent Cochrane review on transcranial direct current stimulation (tDCS) for improving activities of daily living (ADL), and physical and cognitive functioning, in people after stroke showed that there are many ongoing studies (Elsner et al. 2016). A moderate effect of tDCS for improving ADL was found at the end of the intervention period (9 studies, 396 participants; standardized mean difference (SMD) 0.24, 95\% confidence interval (CI) 0.03-0.44) and at follow up (6 studies, 269 participants; SMD 0.31, 95\% CI 0.01-0.62), but not on cognitive functioning. In stroke patients, NIBS studies focus mainly on neglect, aphasia and (working) memory deficits. However, most studies are conducted within experimental settings to show the proof of principle without evaluating long-term effects or improvements in daily life functioning (van Heugten 2017). Recently, it has been suggested that NIBS can be applied as an adjuvant approach to rehabilitation (Wessel et al. 2015). The idea is that it augments the effects of behavioural training by increasing cortical excitability, neuronal plasticity and that it interacts with learning and memory.

Compensatory approaches to cognitive rehabilitation are shown to be the most effective to improve cognitive functioning after stroke and are most often applied in clinical practice (Wilson et al. 2017). In these circumstances, recovery is not achieved by restoring or substituting impaired cognitive functions but by offering patients' strategies to compensate for their impairments at task level. However, most evidence comes from studies on patients with acquired brain injury in which stroke patients are included as one of the major patient groups besides traumatic brain injury (Cicerone et al. 2000, 2005, 2011; Van Heugten et al. 2012). A meta-analysis in which only randomized controlled trials with stroke patients were included concluded that there was insufficient evidence or only evidence of insufficient quality to support recommendations for clinical practice (Gillespie et al. 2015). The Cochrane reviews on cognitive rehabilitation for post-stroke apraxia (West et al. 2008), executive dysfunctioning following stroke (Chung et al. 2013), prevention and treatment of post-stroke fatigue (Wu et al. 2015) and occupational therapy for cognitive impairments post-stroke (Hoffmann et al. 2010) came to the same conclusion about the lack of high-quality RCTs or positive outcomes. Recent Cochrane reviews have added to this evidence. 
In the Cochrane review on cognitive rehabilitation for memory deficits following stroke, 13 RCTs including 514 participants were selected (das Nair et al. 2016). The authors conclude that memory rehabilitation has beneficial effects on subjective measures of memory in the short term (7 RCTs, $n=215$; SMD 0.36 , 95\% CI $0.08-0.64, P=0.01$, moderate quality of evidence), but long-term effects could not be substantiated statistically beyond trend level (3 RCTs, $n=149$; SMD 0.31, 95\% CI -0.02 to $0.64, P=0.06$, low quality of evidence). The results do not show any significant effect of memory rehabilitation on objective memory tests, mood, functional abilities or quality of life. The authors conclude that more robust, welldesigned high-quality trials are necessary.

A similar conclusion was drawn by Loetscher and Lincoln (2013) in their Cochrane review on attention deficits following stroke including 6 RCTs with 223 patients in total. A statistically significant effect was found in favour of cognitive rehabilitation when compared with control for immediate effects on measures of divided attention (SMD 0.67, 95\% CI 0.35-0.98; $P$ value $<0.0001 ; 4$ trials, 165 participants) but no significant effects on global attention (2 studies, 53 participants; $P$ value $=0.06)$, or other attentional domains ( 6 studies, 223 participants; $P$ value $\geq 0.16$ ) or functional outcomes ( 3 studies, 109 participants; $P$ value $\geq 0.21$ ). Meta-analyses demonstrated no statistically significant effect of cognitive rehabilitation for persisting effects on global measures of attention (2 studies, 99 participants; standardized mean difference (SMD) 0.16, 95\% confidence interval $(\mathrm{CI})-0.23$ to $0.56 ; P$ value $=0.41)$, standardized attention assessments ( 2 studies, 99 participants; $P$ value $\geq 0.08$ ) or functional outcomes ( 2 studies, 99 participants; $P$ value $\geq 0.15$ ).

Taking only Cochrane reviews on stroke patients into account, however, has the danger of throwing away the baby with the bathwater. Many evidence-based cognitive rehabilitation programs are available and used in clinical practice all over the world (Wilson et al. 2017). Evidence is often based on samples of mixed aetiologies including stroke patients among other patient groups (mostly traumatic brain injury). In a series of systematic reviews on evidence-based cognitive rehabilitation by Cicerone et al. (2000, 2005, 2011), practice standards, guidelines and options are formulated on the basis of studies in patients with acquired brain injury. Compensatory strategy training and the use of external aids have been shown to be effective for memory deficits, reduced speed of information processing (Time Pressure Management), executive dysfunctioning (Goal Management Training in combination with problem solving therapy) and apraxia.

Moreover, cognitive impairments hardly ever occur in isolation, which is why in clinical practice many multidomain cognitive rehabilitation programs are offered. Limited evidence shows that these programs are effective in attaining individual goals related to daily life functioning which remained in the long term (Brands et al. 2013; Rasquin et al. 2010). Typically, these programs are low-intensive and consist of a combination of psycho-education and compensatory strategy training. Often, these programs are offered in groups to strengthen the effects of peer support. 


\subsubsection{Pharmacological and Psychological Interventions for Depression and Anxiety After Stroke}

Both pharmacological and psychological treatments to prevent depression after stroke (Hackett et al. 2008a, b) have been investigated. Fourteen trials involving 1515 participants were included in a Cochrane review of which 10 trials involved pharmacological agents and did not show significant effects on preventing depression. The psychological interventions showed small but significant positive effects on mood including problem-solving therapy and motivational interviewing.

The Cochrane review on treatment of depression after stroke (Hackett et al. 2008a, b) included 16 trials in which 13 pharmacological agents were investigated and four trials in which the effect of psychological treatment was examined. In most trials, selective serotonin reuptake inhibitors (SSRIs) were applied and also tricyclic antidepressants (TCAs) were investigated. Moderate significant effects were found on remission of depression (pooled OR 0.47; 95\% CI 0.22-0.98) and also small improvements of scores on depression questionnaires (pooled OR $0.22 ; 95 \% \mathrm{CI}$ 0.09-0.52). There was, however, also a significant increase of neurological and gastro-intestinal side effects. There was no significant improvement in cognitive and ADL functioning nor a reduction of disabilities. Mead et al. (2012) investigated the effect of SSRIs on stroke recovery. In the meta-analysis, 52 trials randomizing 4059 patients to SSRI or control were included, and a positive effect was found on neurological deficits (SMD $-1.00,95 \%$ CI -1.26 to $-0.75 ; 29$ trials, 2011 participants), ADL dependence, level of disabilities (SMD 0.91, 95\% CI 0.60-1.22; 22 trials, 1343 participants), anxiety (SMD $-0.77,95 \% \mathrm{CI},-1.52$ to $-0.02 ; 8$ trials, $n=413)$ and depression (SMD was -1.91 (95\% CI, -2.34 to $-1.48 ; 39$ trials, 2728 participants)), however, with considerable variability across trials and substantial risks for bias. For disability, neurological deficits and depression, the effects had been larger when depression was present among participants. The results of this review tentatively support the use of SSRIs in stroke survivors with depression and provide evidence for clinically relevant positive treatment effects not only in the emotional domain.

The psychological interventions in the review of Hackett et al. (2008a, b) involved problem-solving therapy in combination with counselling, cognitive behavioural therapy, motivational interviewing and a combination of support and education, but no significant effects were found. Later studies on behavioural interventions for post-stroke depression show more positive results. The CALM (Communication and Low Mood) intervention for stroke patients with aphasia was effective in improving mood (Thomas et al. 2013) and was cost-effective over a period of 6 months in comparison to care as usual (Humphreys et al. 2015). In a study by Mitchell et al. (2009) patients $(n=101)$ received a short psychosocial intervention in addition to antidepressants which led to lower depression scores and better remission both in the short and the long term. Home-based supportive care also has a positive effect on mood in home-dwelling stroke patients (Huang et al. 2017). Recently, a scientific statement on post-stroke depression was published (Towfighi et al. 2017), summarizing seven studies on brief psychosocial interventions for reducing depression showing a positive effect. Neuro-modulation, stroke 
liaison workers and self-management programs did not have a positive effect. A meta-analysis on the effect of physical exercise on depression in neurological disorders showed a positive effect of physical exercise, preferably those meeting physical activity guidelines, on the reduction of depressive symptoms (26 trials, 1324 participants; effect size $0.2895 \%$ confidence interval 0.15-0.41) (Adamson et al. 2015). A higher effect size (0.38) was found for studies that met physical activity guidelines versus those that did not (0.19). It has to be noted though that only 2 of the 26 trials included stroke patients.

Only three trials have been conducted in which treatment of anxiety post-stroke was investigated according to the most recent Cochrane review (Knapp et al. 2017). Due to small sample sizes, methodological concerns and adverse effects, recommendations for clinical practice cannot be given. In case of emotionalism after stroke (i.e. unwanted laughing or crying), a Cochrane review including seven trails showed that antidepressants can reduce the frequency and severity of crying or laughing episodes ( 7 studies, 239 participants). On the basis of five trials (213 participants), a large effect was found in a 50\% reduction of emotionalism but with a wide confidence interval showing a small positive effect and in one study even a negative effect (Hackett et al. 2010). There is not one specific pharmacological agent.

\subsubsection{Managing Post-stroke Fatigue}

The effects of treatment of post-stroke fatigue are still limited. In the most recent Cochrane review, 12 trials with 703 participants were selected, but only 6 trails could be used for the meta-analysis (Wu et al. 2015). Five pharmacological interventions and two non-pharmacological interventions (fatigue education and mindfulness-based stress reduction) were investigated, but effects were small and the studies were not without risk of bias. Since post-stroke fatigue is multifactorial in nature with physical, cognitive, mental components and individual differences in the way people cope with fatigue, there is not one treatment that will fit all patients' needs (Visser-Keizer et al. 2015; Malley 2017). Psychosocial treatment and physical activity seem promising for the management of post-stroke fatigue but highquality effect studies are necessary (Kutlubaev et al. 2015).

\subsubsection{Comprehensive Neuropsychological Rehabilitation}

The direct consequences of a stroke may also lead to secondary psychosocial problems, which hinder independent functioning and participation in society. The complexity of these problems requires comprehensive rehabilitation programs. Comprehensive neuropsychological (holistic) rehabilitation is aimed at cognitive, emotional, behavioural and social consequences after stroke, taking into account the personal and environmental factors as well. The evidence is still limited but findings suggest that such programs can improve community integration, functional independency and productivity, even many years after the injury (Cicerone et al. 2011). These programs can be divided into neurobehavioural interventions, residential community reintegration and day treatment programs (Geurtsen et al. 2010). Day treatment programs have the highest level of evidence leading to a reduction in 
psychosocial problems, a higher level of community integration and an increase in employment. These programs are typically group-based and offer a combination of individual and group therapy. One of the essential components of such programs is psycho-education about the brain injury and its consequences both for patients and caregivers. Every stroke patient and their primary caregivers should receive information about the potential consequences of stroke.

A Cochrane review on information provision after stroke included 21 trials involving 2289 patients and 1290 carers (Forster et al. 2012). This review shows that information improves patients' (SMD 0.29, 95\% CI 0.12-0.46) and more so caregivers' knowledge (SMD 0.74, 95\% CI 0.06-1.43) and aspects of satisfaction (odds ratio (OR) 2.07, 95\% CI 1.33-3.23, $P=0.001$ ) and reduces patient depression (mean difference (MD) $-0.52,95 \% \mathrm{CI}-0.93$ to -0.10 ). The best way to provide information is not clear yet, but active involvement of patients and carers has a higher effect on patient mood.

\section{The Holistic Approach to Rehabilitation}

Kurt Goldstein can probably be regarded as the grandparent of holistic rehabilitation arguing that we should look at the whole aspects of a situation and not one isolated part such as word finding difficulties (Goldstein 1919, 1942; Boake 1996). Both Goldstein and later Ben-Yishay (1996) recognized that it is futile to separate the cognitive, social, emotional and functional aspects of brain injury given that how we feel affects how we think, remember, communicate, solve problems and behave. This is the core of the holistic approach. As Ben-Yishay and Prigatano said in 1990, holistic rehabilitation "...consists of well integrated interventions that exceed in scope, as well as in kind, those highly specific and circumscribed interventions which are usually subsumed under the term "cognitive remediation"' (BenYishay and Prigatano 1990, p. 40).

Diller (1976), Ben-Yishay (1978) and Prigatano (1986) pioneered the holistic approach which is now seen as one of the most effective ways of providing cognitive rehabilitation to survivors of brain injury. This approach is now much in evidence (Wilson et al. 2009). Holistic programs are concerned with increasing a client's awareness, alleviating cognitive deficits, developing compensatory skills and providing vocational counselling. All such programs provide a mixture of individual and group therapy. They differ from the combined approach primarily in their recognition of the importance of treating emotional problems at the same time as treating the cognitive and social difficulties. Thus, inherent in the holistic approach are theories and models of emotion, which are becoming increasingly important in cognitive rehabilitation, as evidenced, for example by a special issue of the journal Neuropsychological rehabilitation focussing entirely on biopsychosocial approaches in neuropsychological rehabilitation (Williams and Evans 2003).

Ben-Yishay and Prigatano (1990) provide a model of hierarchical stages in the holistic approach through which the patient must work in rehabilitation. These are, in order, engagement, awareness, mastery, control, acceptance and identity. Holistic programs, explicitly or implicitly, tend to work through Ben-Yishay's hierarchical stages and are concerned with (1) increasing the individual's awareness of what has 
happened to him or to her, (2) increasing acceptance and understanding of what has happened, (3) providing strategies or exercises to reduce cognitive problems, (4) developing compensatory skills and (5) providing vocational counselling. All holistic programs include both group and individual therapy.

For a further overview of all aspects of neuropsychological rehabilitation after stroke and other forms of brain injuries, we would like to refer to the International Handbook of Neuropsychological Rehabilitation (Wilson et al. 2017).

\subsubsection{Technical Aids}

The use of assistive technology (AT) to compensate for cognitive impairments has become a common element of neuropsychological rehabilitation (Gillespie et al. 2012). In the area of attention, AT can be used to direct attention and support to sustain attention, for instance by tonal cues or automated text messages. Such mobile phone reminders and alarms/timers can also be used as reminders to support episodic memory (Jamieson et al. 2017). Additionally, time and planning management functions are common forms of AT which are nowadays available on any smartphone. In a metaanalysis including seven group studies, the authors concluded that there is strong evidence for the efficacy of prospective prompting memory devices $(d=1.27, p<0.01$; 147 participants) (Jamieson et al. 2015). AT can also be used to assist organization and provide step-by-step support during task performance.

\section{Clinical Pathway/Evidence-Based Recommendations (What, When, Why?)}

Since our recommendations for screening and neuropsychological assessment of post-stroke cognitive impairment and emotional disorders are not systematically based on evidence, they are not presented with ratings of quality of evidence and strength of recommendations, but rather reflect expert opinion.

The evidence, quality ratings and conclusions are summarized in Table 1.

The therapeutic recommendations given below are based on the evidence that had systematically been searched and presented above. The quality of this evidence has been grouped into four categories according to "GRADE" ("Grades of Recommendation, Assessment, Development and Evaluation”) (Owens et al. 2010):

- High quality: further research is unlikely to affect our confidence in the estimation of the (therapeutic) effect.

- Medium quality: further research is likely to affect our confidence in the estimation of the (therapeutic) effect and may alter the estimate.

- Low quality: further research will most likely influence our confidence in the estimation of the (therapeutic) effect and will probably change the estimate.

- Very low quality: any estimation of the (therapy) effect or prognosis is very uncertain. 


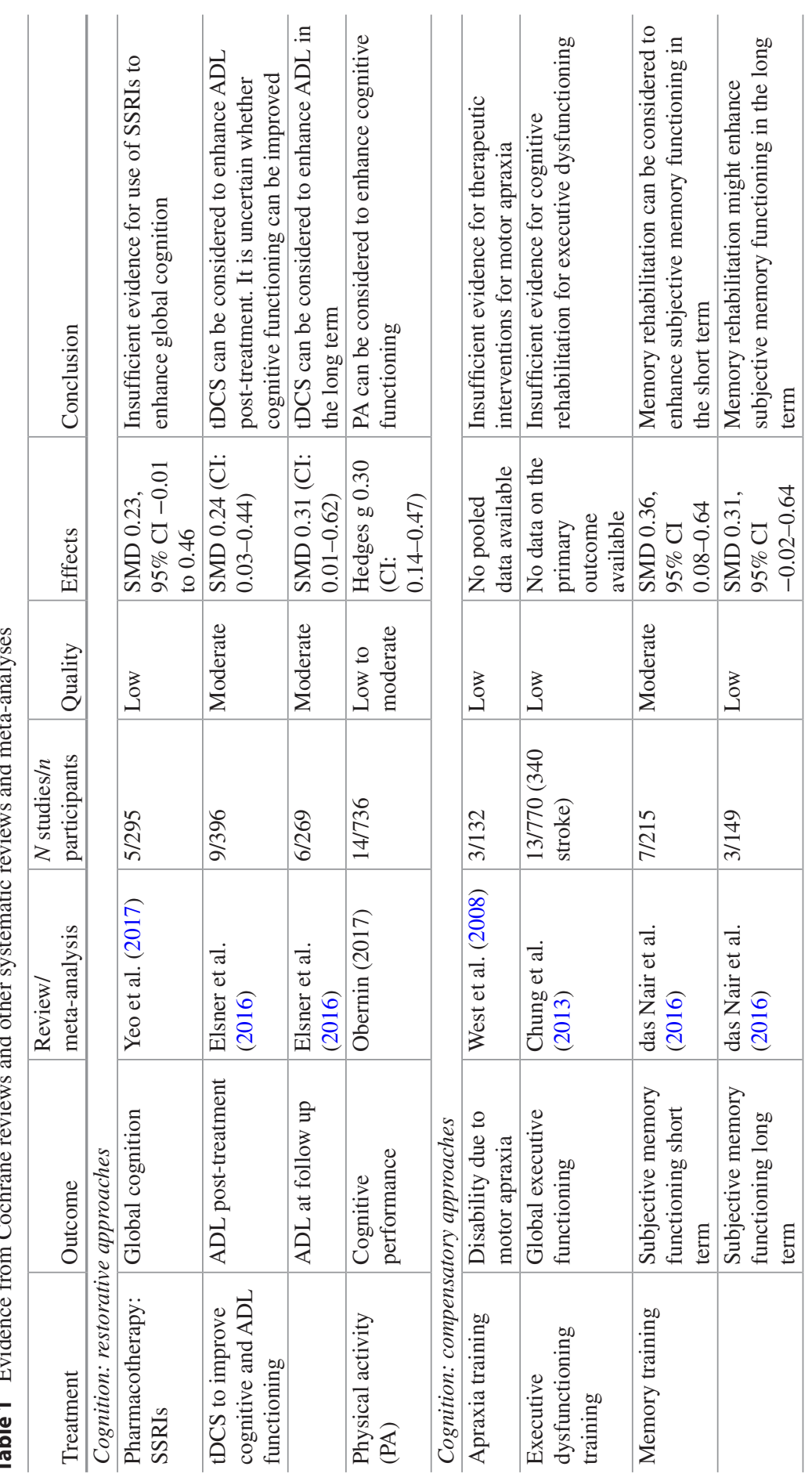




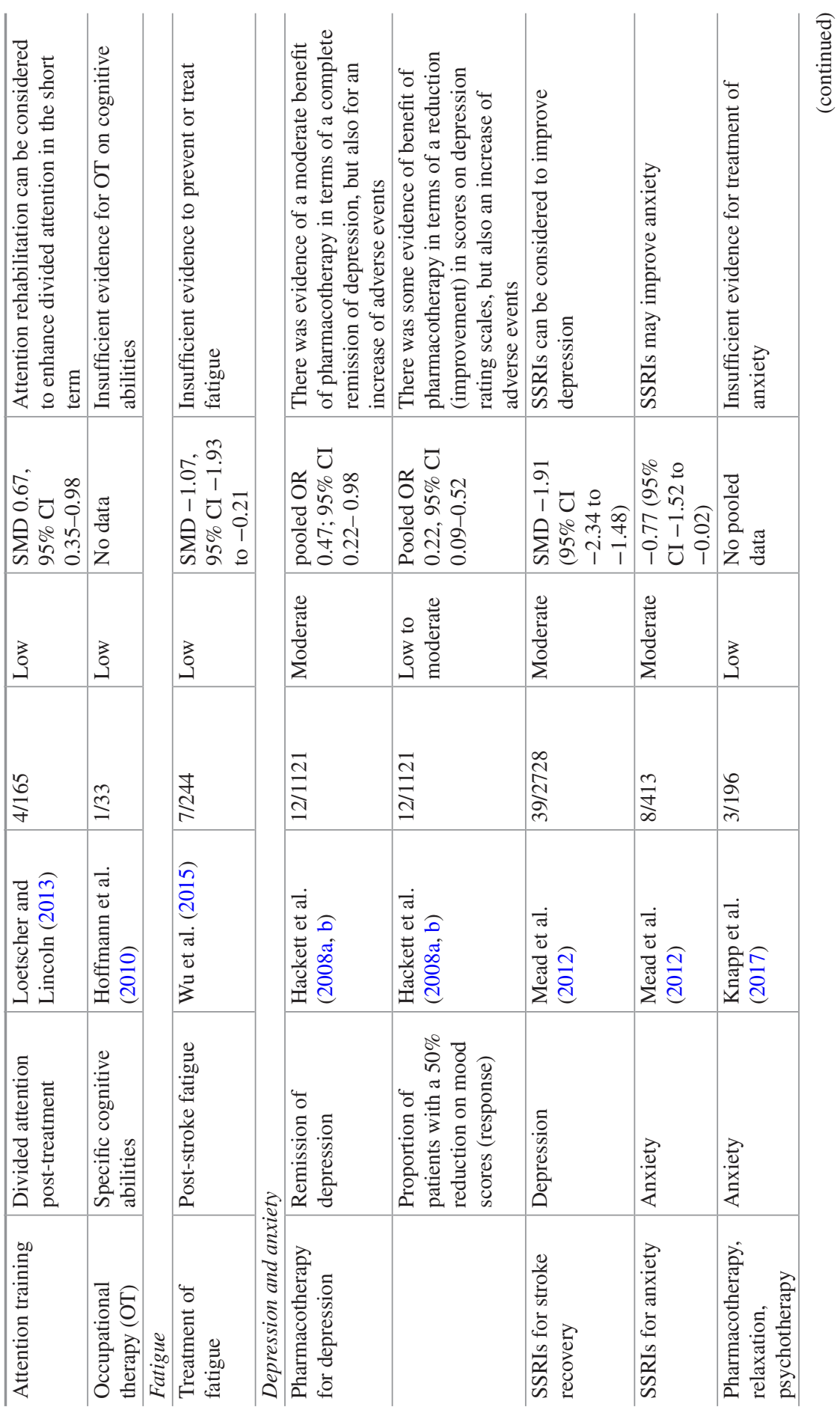




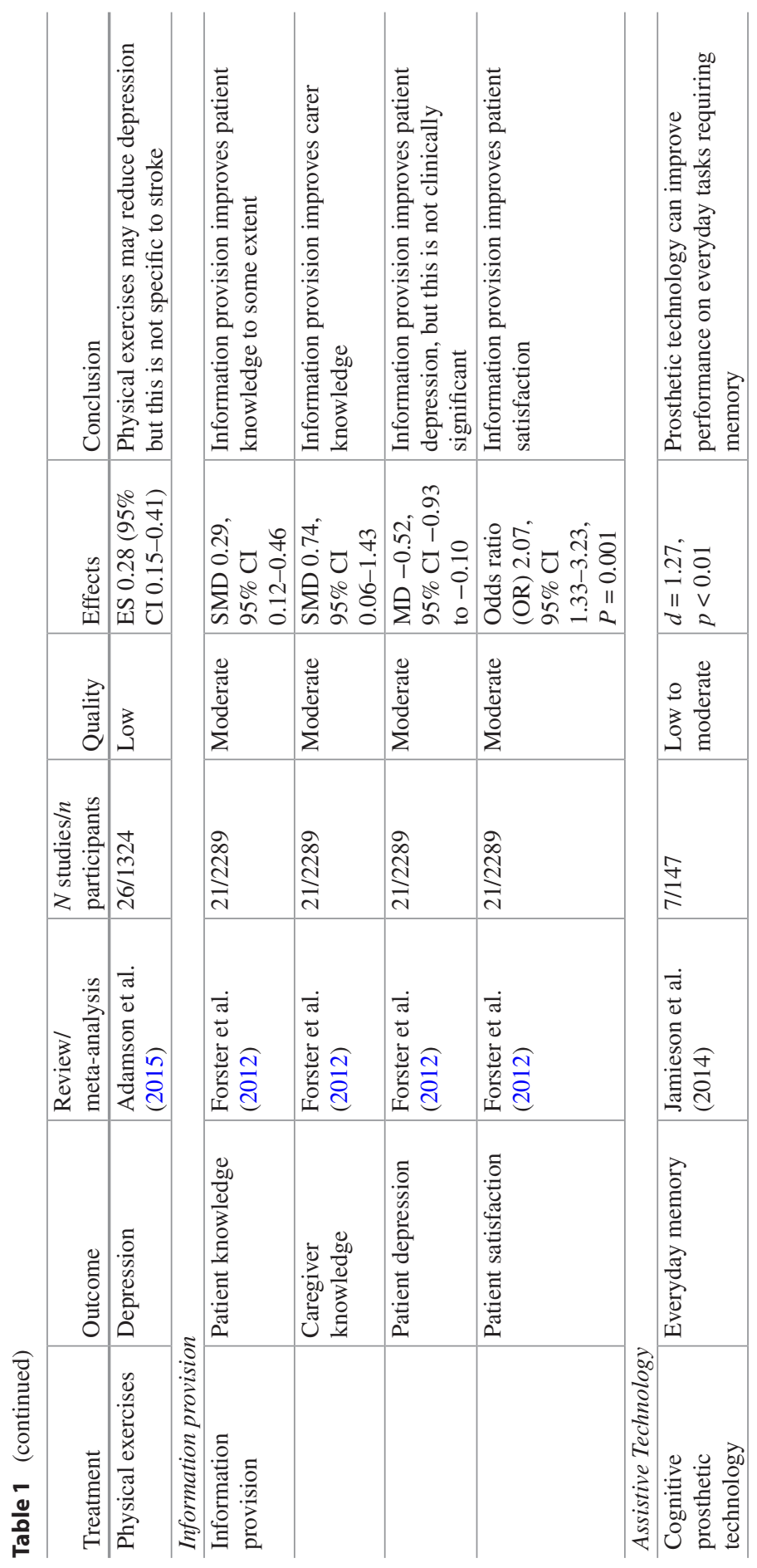


The grading of the recommendations according to GRADE (Schünemann et al. 2013) corresponds to the categories "ought to" (A) (strong recommendation), "should" (B) (weak recommendation). As a third category had been introduced "can" (0) (option) (Platz 2017). Recommendation category A is granted for clinically effective interventions with high-quality evidence support; with medium-quality evidence category B and with low- or very low-quality evidence category 0 can be appropriate. $\mathrm{A}+$ and $\mathrm{B}+$ denote a strong or weak recommendation in favour on an intervention, $\mathrm{A}-$ and $\mathrm{B}-$ against its use.

The recommendations following from the evidence are summarized in Table 2.

\subsection{Cognitive Screening in Hospital}

Every stroke patient should be screened for cognitive and emotional consequences following stroke. Objective cognitive screening should be conducted before the patient is discharged from the hospital to support the decision on the discharge destination and further rehabilitation treatment. Cognitive screening can best be

Table 2 Recommendations for the management of cognition, emotion and fatigue post-stroke

\begin{tabular}{|c|c|c|}
\hline Management & Phase & Recommendation \\
\hline \multicolumn{3}{|c|}{ Screening and Assessment } \\
\hline Cognitive screening & Acute & $\begin{array}{l}\text { Every stroke patient should be screened for } \\
\text { cognitive and emotional consequences } \\
\text { following stroke before hospital discharge to } \\
\text { support the decision on the discharge } \\
\text { destination and further rehabilitation } \\
\text { treatment }\end{array}$ \\
\hline Cognitive assessment & Post-acute & $\begin{array}{l}\text { If cognitive deficits are not present upon early } \\
\text { global cognitive screening or not checked at } \\
\text { all, cognitive functioning should be assessed } \\
\text { again at a later stage. If communication } \\
\text { disorders exist, the method of information } \\
\text { extraction must be modified accordingly for } \\
\text { valid conclusions to be made }\end{array}$ \\
\hline Cognitive assessment & First year & $\begin{array}{l}\text { Both objective and subjective cognitive and } \\
\text { emotional screening should always be } \\
\text { performed during follow-up visits }\end{array}$ \\
\hline $\begin{array}{l}\text { Neuropsychological } \\
\text { assessment }\end{array}$ & $\begin{array}{l}\text { Rehabilitation } \\
\text { and community } \\
\text { reintegration }\end{array}$ & $\begin{array}{l}\text { At the start of rehabilitation, and also when } \\
\text { support is needed for community } \\
\text { reintegration, an extensive } \\
\text { neuropsychological assessment should be } \\
\text { conducted }\end{array}$ \\
\hline \multicolumn{3}{|c|}{ Treatment and Management } \\
\hline Information provision & All phases & $\begin{array}{l}\text { All patients and caregivers should receive } \\
\text { information about the (potential) cognitive } \\
\text { and emotional consequences, including } \\
\text { fatigue, following stroke (level of evidence } \\
\text { 1a, low quality, recommendation } \mathrm{B}+\text { ) }\end{array}$ \\
\hline
\end{tabular}


Table 2 (continued)

\begin{tabular}{|c|c|c|}
\hline Management & Phase & Recommendation \\
\hline $\begin{array}{l}\text { Referral to specialist } \\
\text { services for cognitive, } \\
\text { emotional and behavioral } \\
\text { consequences }\end{array}$ & $\begin{array}{l}\text { From post-acute } \\
\text { onwards }\end{array}$ & $\begin{array}{l}\text { Patients and caregivers should be referred to } \\
\text { relevant follow-up care and } \\
\text { neuropsychological rehabilitation within their } \\
\text { stroke service (level of evidence 5, very low } \\
\text { quality, recommendation B+) } \\
\text { There is no time limit to these programs } \\
\text { which means that patients may also be } \\
\text { supported many years after the injury (level } \\
\text { of evidence 5, very low quality, } \\
\text { recommendation B+) } \\
\text { General practitioners should be informed } \\
\text { about the regional healthcare options for } \\
\text { these problems }\end{array}$ \\
\hline Cognitive rehabilitation & $\begin{array}{l}\text { From post-acute } \\
\text { onwards }\end{array}$ & $\begin{array}{l}\text { Compensatory strategy training and the use } \\
\text { of external and technical aids should be } \\
\text { offered to help stroke patients to deal with } \\
\text { cognitive impairments (level of evidence } 1 \mathrm{~b} \text {, } \\
\text { low quality, recommendation } \mathrm{B}+\text { ). }\end{array}$ \\
\hline $\begin{array}{l}\text { Neuropsychological } \\
\text { rehabilitation aimed at } \\
\text { cognitive, emotional, } \\
\text { behavioral and social } \\
\text { consequences }\end{array}$ & $\begin{array}{l}\text { From post-acute } \\
\text { onwards }\end{array}$ & $\begin{array}{l}\text { Neuropsychological rehabilitation can be } \\
\text { offered by experienced clinical or } \\
\text { neuropsychologists working within a } \\
\text { multidisciplinary team (level of evidence } 5 \text {, } \\
\text { very low quality, recommendation } 0 \text { ). Both } \\
\text { low-intensity and high-intensity (holistic) } \\
\text { group programs can be considered }\end{array}$ \\
\hline Antidepressants & Chronic phase & $\begin{array}{l}\text { SSRIs should be considered when depressive } \\
\text { complaints or emotionalism are long lasting } \\
\text { and become chronic while adverse effects } \\
\text { should be monitored continuously (level of } \\
\text { evidence } 1 \mathrm{a} \text {, moderate quality, } \\
\text { recommendation B+) }\end{array}$ \\
\hline Psychotherapy & All phases & $\begin{array}{l}\text { Problem-solving therapy and motivational } \\
\text { interviewing can be considered to prevent } \\
\text { depressive symptoms post-stroke (level of } \\
\text { evidence } 2 \mathrm{~b} \text {, low quality, recommendation } 0 \text { ) }\end{array}$ \\
\hline
\end{tabular}

Classification of evidence level (1a to 5 according to the "Oxford Center for Evidence-Based Medicine - Levels of Evidence", last version from March 2009, http://www.cebm.net/Oxfordcentre-evidence-based-medicine). Rating of quality of evidence (very low to high) and categories of recommendations $(0, \mathrm{~B}+, \mathrm{A}+)$ according to GRADE ("Grades of Recommendation, Assessment, Development and Evaluation"); for explanation see text

These ratings are only given for evidence-based recommendation for interventions (not for screening and assessment: expert opinion)

performed using the Montreal Cognitive Assessment (MoCA) because this is the most sensitive instrument for this purpose. A cutoff value of 24 is recommended. The Mini Mental State Examination (MMSE) should not be used because it was not designed for this purpose and is therefore not sufficiently sensitive. If cognitive deficits are found, referral for neuropsychological rehabilitation should follow. If cognitive deficits are not present upon early global cognitive screening or not checked at 
all, cognitive functioning should be assessed again at a later stage because cognitive deficits are easily missed during hospital admission when the patient has good functional outcome in terms of motor and language functioning (i.e. the walking and talking patient).

\subsection{Cognitive and Emotional Screening at Routine Follow-Up}

Most stroke patients are invited to visit a neurological outpatient clinic for a neurological follow-up and secondary prevention purposes. We recommend that both objective and subjective cognitive and emotional screening are always performed during these visits, which can be completed by a specialized stroke nurse. Cognitive deficits are easily missed during hospital admission. Cognitive functioning may not have been assessed before. Additionally, global cognitive screening may not be enough to pick up cognitive problems which arise from the more complex daily life challenges and return to prior activities such as work. For this reason, subjective cognitive complaints should be surveyed as well. Patients and their informal caregivers may differ in their experiences of cognitive consequences, which is why problems in cognitive functioning experienced by the primary caregiver should also be taken into account in the assessment. The stroke-specific Checklist for Cognition and Emotion (CLCE-24) can be used for this purpose.

Screening for emotional problems can be done with the Hospital Anxiety and Depression Scale (HADS), which is the only sensitive tool that also incorporates anxiety. The recommended cutoff value for each subscale (i.e. depression and anxiety) is seven. Post-stroke fatigue can best be screened with the Fatigue Severity Scale (FSS) using four as the cutoff point.

Most of these screening instruments can be used by specialized stroke nurses who have been trained in using and interpreting these instruments. Screening for the less-visible neuropsychological consequences of stroke should be done on a regular basis. If patients and caregivers do not report problems spontaneously, this does not necessarily mean that they are not present. If cognitive and emotional problems are experienced which interfere with daily life functioning, referral for neuropsychological rehabilitation should follow. At the start of rehabilitation, and also when support is needed for community reintegration, an extensive neuropsychological assessment should be conducted.

\subsection{Neuropsychological Rehabilitation}

All patients and caregivers should receive information about the potential cognitive and emotional consequences, including fatigue, following stroke because it improves patients' and caregivers' knowledge and reduces the level of depression in patients (level of evidence 1a, low quality, recommendation B+). Active and personalized information provision is preferred. Information can be given by 
any experienced member of the treatment team and should be repeated as often as necessary and possible.

Cognitive problems may arise at a later stage when the patient is discharged home and environmental demands are increasing. Resuming to prior activities, especially returning to work, may lead to problems which were not detected earlier. Patients and caregivers should be referred to relevant follow-up care and neuropsychological rehabilitation within their stroke service (level of evidence 5, very low quality, recommendation $\mathrm{B}+$ ). General practitioners should be informed about the regional healthcare options for these problems.

Compensatory strategy training and the use of external and technical aids should be offered to help stroke patients with cognitive impairments to improve their daily life functioning (level of evidence $1 \mathrm{~b}$, low quality, recommendation $\mathrm{B}+$ ). Psycho-education and strategy training can easily be combined in lowintensity group-based programs aimed at individualized patient-centred goals. Regional low-frequency or national high-intensity (holistic) outpatient neuropsychological rehabilitation programs may be indicated because of the complex interplay between cognitive, emotional and social consequences. There is no time limit to these programs which means that patients may also be supported many years after the injury (level of evidence 5, very low quality, recommendation $\mathrm{B}+$ ). New problems may occur in the chronic phase after stroke when environmental demands are changing or increasing. Chronicity does not necessarily imply stability. Neuropsychological rehabilitation can be offered by experienced clinical or neuropsychologists working within a multidisciplinary team in which occupational therapists will address the link to the patient's daily life functioning and societal participation (level of evidence 5, very low quality, recommendation 0).

Clinicians should be aware of the influence of post-stroke fatigue on daily life functioning and societal participation. Although evidence is limited, psychosocial treatment and physical activity seem promising for the management of post-stroke fatigue (level of evidence 5, very low quality, recommendation 0 ).

In the first months, post-stroke antidepressant pharmacotherapy is only recommended if the process of rehabilitation is hindered by emotional problems. Increasing motivation for and participation in rehabilitation is the target for treatment. SSRIs should be considered when depressive complaints or emotionalism are long lasting and become chronic while adverse effects should be monitored continuously (level of evidence 1a, moderate quality, recommendation $\mathrm{B}+$ ). Problem-solving therapy and motivational interviewing can be considered to prevent depressive symptoms post-stroke (level of evidence $2 \mathrm{~b}$, low quality, recommendation 0). Psycho-education should always be offered to both prevent and reduce anxiety, stress and depressive complaints in both patients and caregivers (level of evidence 1a, moderate quality, recommendation $\mathrm{B}+)$. 


\subsection{New Developments}

There is no effective treatment for deficits in social cognition or emotion regulation yet, but professionals should be aware of problems in these areas, especially in relation to caregiver burden.

Restorative approaches such as pharmacotherapy, CBCR and NIBS can be offered to improve cognitive functioning but effects are limited to cognitive functions in testing situations (level of evidence $2 \mathrm{~b}$ to $1 \mathrm{a}$, low quality, recommendation 0 ). These forms of rehabilitation are primarily focused on alleviating cognitive impairment while neuropsychological rehabilitation is aimed at a broader spectrum of human functioning, also taking into account emotional, behavioural and social functioning, with the ultimate goal to optimize the participation and quality of life of both patients and caregivers. Although promising, restorative approaches in rehabilitation should always be offered only in combination with comprehensive neuropsychological rehabilitation programs aimed at improving daily life functioning and societal participation.

\section{References}

Aben I, Denollet J, Lousberg R, Verhey F, Wojciechowski F, Honig A (2002) Personality and vulnerability to depression in stroke patients: a 1-year prospective follow-up study. Stroke 33:2391-2395

Adamson BC, Ensari I, Motl RW (2015) Effect of exercise on depressive symptoms in adults with neurologic disorders: a systematic review and meta-analysis. Arch Phys Med Rehabil 96(7):1329-1338

Albert SJ, Kesselring J (2012) Neurorehabilitation of stroke. J Neurol 259(5):817-892

Angelelli P, Paolucci S, Bivona U, Piccardi L, Ciurli P, Cantagallo A, Antonucci G, Fasotti L, Di Santantonio A, Grasso MG, Pizzamiglio L (2004) Development of neuropsychiatric symptoms in poststroke patients: a cross-sectional study. Acta Psychiatr Scand 110(1):55-63

Arts MLJ, Kwa VIH, Dahmen R (2008) High satisfaction with an individualised stroke care programme after hospitalisation of patients with a TIA or minor stroke: a pilot study. Cerebrovasc Dis 25:566-571

Barker-Collo S, Feigin V (2006) The impact of neuropsychological deficits on functional stroke outcomes. Neuropsychol Rev 16:35-64

Barker-Collo S, Feigin V, Parag V, Lawes C, Senior H (2010) Auckland stroke outcomes study. Part 2: cognition and functional outcomes 5 years post stroke. Neurology 75:1608-1615

Ben-Yishay Y (ed) (1978) Working approaches to remediation of cognitive deficits in brain damaged persons (Rehabilitation Monograph). New York University Medical Center, New York

Ben-Yishay Y (1996) Reflections on the evolution of the therapeutic milieu concept. Neuropsychol Rehabil 6(4):327-343

Ben-Yishay Y, Prigatano GP (1990) Cognitive remediation. In: Rosenthal M, Griffith ER, Bond MR, Miller JD (eds) Rehabilitation of the adult and child with traumatic brain injury, 2nd edn. F. A. Davis, Philadelphia, pp 393-409

Boake C (1996) Editorial: historical aspects of neuropsychological rehabilitation. Neuropsychol Rehabil 6:241-243 
Brands IM, Bouwens SF, Wolters Gregório G, Stapert SZ, van Heugten CM (2013) Effectiveness of a process-oriented patient-tailored outpatient neuropsychological rehabilitation programme for patients in the chronic phase after ABI. Neuropsychol Rehabil 23(2):202-215

Burton L, Tyson SF (2015) Screening for cognitive impairment after stroke: a systematic review of psychometric properties and clinical utility. J Rehabil Med 47(3):193-203

Chung CS, Pollock A, Campbell T, Durward BR, Hagen S (2013) Cognitive rehabilitation for executive dysfunction in adults with stroke or other adult non-progressive acquired brain damage. Cochrane Database Syst Rev (4):CD008391

Cicerone KD, Dahlberg C, Kalmar K, Langenbahn DM, Malec JF, Bergquist TF, Felicetti T, Giacino JT, Harley JP, Harrington DE, Herzog J, Kneipp S, Laatsch L, Morse PA (2000) Evidence-based cognitive rehabilitation: recommendations for clinical practice. Arch Phys Med Rehabil 81(12):1596-1615

Cicerone KD, Dahlberg C, Malec JF, Langenbahn DM, Felicetti T, Kneipp S, Ellmo W, Kalmar K, Giacino JT, Harley JP, Laatsch L, Morse PA, Catanese J (2005) Evidence-based cognitive rehabilitation: updated review of the literature from 1998 through 2002. Arch Phys Med Rehabil 86(8):1681-1692

Cicerone KD, Langenbahn DM, Braden C, Malec JF, Kalmar K, Fraas M, Felicetti T, Laatsch L, Harley JP, Bergquist T, Azulay J, Cantor J, Ashman T (2011) Evidence-based cognitive rehabilitation: updated review of the literature from 2003 through 2008. Arch Phys Med Rehabil 92(4):519-530

Cumming TB, Mead G (2017) Classifying post-stroke fatigue: Optimal cut-off on the fatigue assessment scale. J Psychosom Res 103:147-149

Cumming TB, Packer M, Kramer SF, English C (2016) The prevalence of fatigue after stroke: a systematic review and meta-analysis. Int J Stroke 11(9):968-977

das Nair R, Cogger H, Worthington E, Lincoln NB (2016) Cognitive rehabilitation for memory deficits after stroke. Cochrane Database Syst Rev 9(9):CD002293

de Graaf JA, van Mierlo M, Post M, Achterberg W, Kapelle J, Visser-Meily J (2018) Long-term restrictions in participation in stroke survivors under and over 70 years of age. Disabil Rehabil 40(6):637-645

De Wit L, Putman K, Baert I, Lincoln LB, Angst F, Beyens H et al (2008) Anxiety and depression in the first six months after stroke. A longitudinal multicentre study. Disabil Rehabil 30:1858-1866

Diller L (1976) A model for cognitive retraining in rehabilitation. Clin Psychol 29:13-15

Duits AA, Munnecom T, van Heugten CM, Van Oostebrugge RJ (2008) Cognitive and emotional consequences in the early phase after stroke: complaints versus performance. JNNP 79(2):143-146

Duncan PW, Samsa GP, Weinberger M, Goldstein LB, Bonito A, Witter DM, Enarson C, Matchar D (1997) Health status of individuals with mild stroke. Stroke 28(4):740-745

Edwards DF, Hahn M, Baum C, Dromerick AW (2006) The impact of mild stroke on meaningful activity and life satisfaction. J Stroke Cerebrovasc Dis 15:151-157

Elsner B, Kugler J, Pohl M, Mehrholz J (2016) Transcranial direct current stimulation (tDCS) for improving activities of daily living, and physical and cognitive functioning, in people after stroke. Cochrane Database Syst Rev 3(3):CD009645

Fens M, van Heugten C, Beusmans G, Limburg M, Haeren R, Kaemingk A, Metsemakers J (2013) Not as transient: patients with transient ischaemic attack or minor stroke experience cognitive and communication problems; an exploratory study. Eur J Gen Pract 19:11-16

Forster A, Brown L, Smith J, House A, Knapp P, Wright J, Young J (2012) Information provision for stroke patients and their caregivers. Cochrane Database Syst Rev 11(11):CD001919

Geurtsen GJ, van Heugten CM, Martina JD, Geurts AC (2010) Comprehensive rehabilitation programmes in the chronic phase after severe brain injury: a systematic review. J Rehabil Med 42(2):97-110

Gillespie A, Best C, O'Neill B (2012) Cognitive function and assistive technology for cognition: a systematic review. J Int Neuropsychol Soc 18:1-19 
Gillespie DC, Bowen A, Chung CS, Cockburn J, Knapp P, Pollock A (2015) Rehabilitation for post-stroke cognitive impairment: an overview of recommendations arising from systematic reviews of current evidence. Clin Rehabil 29(2):120-128

Goldstein K (1919) Die Behandlung, Fürsorge und Begutachtung der Hirnverletzten. Zugleich ein Beitrag zur Verwendung psychologischer Methoden in der Klinik. F.C.W. Vogel, Leipzig

Goldstein K (1942) After-effects of brain injuries in war: their evaluation and treatment. Grune \& Stratton, New York

Hachinski V, Iadecola C, Petersen RC, Breteler MM, Nyenhuis DL, Black SE, Powers WJ, DeCarli C, Merino JG, Kalaria RN, Vinters HV, Holtzman DM, Rosenberg GA, Wallin A, Dichgans M, Marler JR, Leblanc GG (2006) National Institute of Neurological Disorders and StrokeCanadian Stroke Network vascular cognitive impairment harmonization standards. Stroke 37(9):2220-2241

Hackett ML, Anderson C, House A, Halteh A (2008a) Interventions for preventing depression after stroke. Cochrane Database Syst Rev (3):CD003689

Hackett ML, Anderson CS, House A, Xia J (2008b) Interventions for treating depression after stroke. Cochrane Database Syst Rev (4):CD003437

Hackett ML, Yang M, Craig S, Anderson C, Horrocks J, House A (2010) Pharmaceutical interventions for emotionalism after stroke. Cochrane Database Syst Rev (2):CD003690

Hoffmann T, Bennett S, Koh CL, McKenna K (2010) Occupational therapy for cognitive impairment in stroke patients. Cochrane Database Syst Rev 2010(9):CD006430

Huang HC, Huang YC, Lin MF, Hou WH, Shyu ML, Chiu HY, Chang HJ (2017) Effects of homebased supportive care on improvements in physical function and depressive symptoms in patients with stroke: a meta-analysis. Arch Phys Med Rehabil 98(8):1666-1677

Humphreys I, Thomas S, Phillips C, Lincoln N (2015) Cost analysis of the communication and low mood (CALM) randomised trial of behavioural therapy for stroke patients with aphasia. Clin Rehabil 29(1):30-41

Jamieson M, Cullen B, McGee-Lennon M, Brewster B, Evans J (2015) The efficacy of cognitive prosthetic technology for people with memory impairments: a systematic review and metaanalysis. Neuropsychol Rehabi 24(3-4):419-444

Jamieson M, Cullen B, McGee-Lennon M, Brewster B, Evans J (2017) Technological memory aid use by people with acquired brain injury. Neuropsychol Rehabil 27(6):919-936

Knapp P, Campbell Burton C, Holmes J, Murray J, Gillespie D, Lightbody E, Watkins C, Chun H-Y, Lewis S (2017) Interventions for treating anxiety after stroke. Cochrane Database Syst Rev 2017(5):CD008860

Kochanek P, Jackson T, Ferguson N, Carlson S, Simon D et al (2015) Emerging therapies in traumatic brain injury. Semin Neurol 35(1):83-100

Kootker JA, van Mierlo ML, Hendriks JC, Sparidans J, Rasquin SM, de Kort PL, Visser-Meily JM, Geurts AC (2016) Risk factors for symptoms of depression and anxiety one year poststroke: a longitudinal study. Arch Phys Med Rehabil 97(6):919-928

Kouwenhoven SE, Kirkevold M, Engedal K, Kim HS (2011) Depression in acute stroke: prevalence, dominant symptoms, and associated factors. A systematic literature review. Disabil Rehabil 33:539-556

Kutlubaev MA, Mead GE, Lerdal A (2015) Fatigue after stroke--perspectives and future directions. Int J Stroke 10(3):280-281

Langhorne P, Bernhardt J, Kwakkel G (2011) Stroke rehabilitation. Lancet 377(9778): $1693-1702$

Linden T, Samuelson H, Skog I, Blomstrand C (2005) Visual neglect and cognitive impairment in elderly patients late after stroke. Acta Neurol Scand 111:163-168

Loetscher T, Lincoln NB (2013) Cognitive rehabilitation for attention deficits following stroke. Cochrane Database Syst Rev 2013(5):CD002842

Mala H, Rasmussen C (2017) The effect of combined therapies on recovery after acquired brain injury: systematic review of preclinical studies combining enriched environment, exercise, or task-specific training with other therapies. Restor Neurol Neurosci 35:25-64 
Malec J (2017) Assessment for neuropsychological rehabilitation planning. In: Wilson BA, Winegardner J, van Heugten C, Ownsworth T (eds) Neuropsychological rehabilitation: the international handbook. Routledge Taylor \& Francis Group, Cambridge, pp 36-48

Malley D (2017) Managing fatigue in adults after acquired brain injury. In: Wilson BA, Winegardner J, van Heugten C, Ownsworth $\mathrm{T}$ (eds) Neuropsychological rehabilitation: the international handbook. Routledge Taylor \& Francis Group, Cambridge, pp 391-402

Mandliya A, Das A, Unnikrishnan JP, Amal MG, Sarma PS, Sylaja PN (2016) Post-stroke fatigue is an independent predictor of post-stroke disability and burden of care: a path analysis study. Top Stroke Rehabil 23(1):1-7

Mark RE (2012) Good recovery after stroke may hide widespread cognitive deficits. Eur J Neurol 19(7):e61

Mead GE, Hsieh C, Lee R, Kutlubaev MA, Claxton A, Hankey GJ, Hackett ML (2012) Selective serotonin reuptake inhibitors for stroke recovery. Cochrane Database Syst Rev 11(11):CD009286

Mitchell PH, Veith RC, Becker KJ, Buzaitis A, Cain KC, Fruin M et al (2009) Brief psychosocialbehavioral intervention with antidepressant reduces poststroke depression significantly more than usual care with antidepressant: living well with stroke: randomized, controlled trial. Stroke 40(9):3073-3078

Moran GM, Fletcher B, Feltham MG, Calvert M, Sackley C, Marshall T (2014) Fatigue, psychological and cognitive impairment following transient ischaemic attack and minor stroke: a systematic review. Eur J Neurol 21:1258-1267

Muus I, Petzold M, Ringsberg KC (2010) Health-related quality of life among Danish patients 3 and 12 months after TIA or mild stroke. Scand J Caring Sci 24:211-218

Neren D, Johnson M, Legon W, Bachour S, Lang G, Divani A (2016) Vagus nerve stimulation and other neuromodulation methods for treatment of traumatic brain injury. Neurocrit Care 24:308-319

Nijsse B, van Heugten CM, van Mierlo ML, Post MW, de Kort PL, Visser-Meily JM (2017a) Psychological factors are associated with subjective cognitive complaints 2 months poststroke. Neuropsychol Rehabil 27(1):99-115

Nijsse B, Visser-Meily JM, van Mierlo ML, Post MW, de Kort PL, van Heugten CM (2017b) Temporal evolution of poststroke cognitive impairment using the montreal cognitive assessment. Stroke 48(1):98-104

Nys G, Van Zandvoort MJ, De Kort PL, Jansen BP, Van der Worp HB, Kapelle LJ, De Haan EH (2005) Domain-specific cognitive recovery after first-ever stroke: a follow-up study of 111 cases. J Int Neuropsychol Soc 11(7):795-806

Oberlin LE, Waiwood AM, Cumming TB, Marsland AL, Bernhardt J, Erickson KI (2017) Effects of physical activity on poststroke cognitive function: a meta-analysis of randomized controlled trials. Stroke 48(11):3093-3100

Owens DK, Lohr KN, Atkins D, Treadwell JR, Reston JT, Bass EB, Chang S, Helfand M (2010) AHRQ series paper 5: grading the strength of a body of evidence when comparing medical interventions--agency for healthcare research and quality and the effective health-care program. J Clin Epidemiol 63:513-523

Platz T (2017) Practice guidelines in neurorehabilitation. Neurol Int Open 1:E148-E152

Prigatano GP (1986) Personality and psychosocial consequences of brain injury. In: Prigatano GP, Fordyce DJ, Zeiner HK, Roueche JR, Pepping M, Wood BC (eds) Neuropsychological rehabilitation after brain injury. The Johns Hopkins University Press, Baltimore, pp 29-50

Radman N, Staub F, Aboulafia-Brakha T, Berney A, Bogousslavsky J, Annoni JM (2012) Poststroke fatigue following minor infarcts. A prospective study. Neurology 79:1422-1427

Rasquin S, Verhey F, Lousberg R, Winkens I, Lodder J (2002) Vascular cognitive disorders: memory, mental speed and cognitive flexibility after stroke. J Neurol Sci 203-204: 115-119

Rasquin S, Lodder J, Ponds R, Einkens I, Jolles J, Verhey FR (2004) Cognitive functioning after stroke: a one-year follow up study. Dement Geriatr Cogn Disord 18(2):138-144 
Rasquin SM, Bouwens SF, Dijcks B, Winkens I, Bakx WG, van Heugten CM (2010) Effectiveness of a low intensity outpatient cognitive rehabilitation programme for patients in the chronic phase after acquired brain injury. Neuropsychol Rehabil 20(5):760-777

Schünemann H, Brożek J, Guyatt G, Oxman A (2013) GRADE handbook for grading quality of evidence and strength of recommendations. The GRADE Working Group. Updated October 2013. www.guidelinedevelopment.org/handbook

Sivakumar L, Kate M, Jeerakathil T, Camicioli R, Buck B, Butcher K (2014) Serial Montreal cognitive assessments demonstrate reversible cognitive impairment in patients with acute transient ischemic attack and minor stroke. Stroke 45(6):1709-1715

Stolwyk RJ, O’Neill MH, McKay AJ, Wong DK (2014) Are cognitive screening tools sensitive and specific enough for use after stroke?: a systematic literature review. Stroke 45(10): 3129-3134

Suenkeler IH, Nowak M, Misselwitz B, Kugler C, Schreiber W, Oertel WH, Back T (2002) Timecourse of health-related quality of life as determined 3, 6 and 12 months after stroke: relationship to neurological deficit, disability and depression. J Neurol 249:1160-1167

Thomas SA, Walker MF, Macniven JA, Haworth H, Lincoln NB (2013) Communication and low mood (CALM): a randomized controlled trial of behavioural therapy for stroke patients with aphasia. Clin Rehabil 27(5):398-408

Towfighi A, Ovbiagele B, El Husseini N, Hackett ML, Jorge RE, Kissela BM, Mitchell PH, Skolarus LE (2017) Posstroke depression: A scientific statement for healthcare professionals from the american heart assocaition/american stroke association. 48(2):e30-e43

van der Kemp J, Kruithof WJ, Nijboer TCW, van Bennekom CAM, van Heugten C, Visser-Meily JMA (2017) Return to work after mild-to-moderate stroke: work satisfaction and predictive factors. Neuropsychol Rehabil 29(4):638-653

Van der Zwaluw C, Valentijn S, Mark-Nieuwenhuis R, Rasquin S, van Heugten C (2011) Cognitive functioning in the acute phase post stroke: a predictor for discharge destination? J Stroke Cerebrovasc Dis 20(6):549-555

van Dijk EJ, de Leeuw FE (2012) Recovery after stroke: more than just walking and talking again If you don't look for it, you won't find it. Eur J Neurol 19(2):189-190

van Dijk MJ, de Man-van Ginkel JM, Hafsteinsdóttir TB, Schuurmans MJ (2016) Identifying depression post-stroke in patients with aphasia: a systematic review of the reliability, validity and feasibility of available instruments. Clin Rehabil 30(8):795-810

Van Heugten C (2017) Novel forms of cognitive rehabilitation. In: Wilson BA, Winegardner J, van Heugten C, Ownsworth T (eds) Neuropsychological rehabilitation: the international handbook. Routledge Taylor \& Francis Group, Cambridge, pp 425-433

van Heugten C, Rasquin S, Winkens I, Beusmans G, Verhey F (2007) Checklist for cognitive and emotional consequences following stroke (CLCE-24): development, usability and quality of the self-report version. Clin Neurol Neurosurg 109(3):257-262

Van Heugten C, Gregório GW, Wade D (2012) Evidence-based cognitive rehabilitation after acquired brain injury: a systematic review of content of treatment. Neuropsychol Rehabil 22(5):653-673

Van Heugten CM, Walton L, Hentschel U (2015) Can we forget the Mini-Mental State Examination? A systematic review of the validity of cognitive screening instruments within one month after stroke. Clin Rehabil 29(7):694-704

van Heugten CM, Ponds RW, Kessels RP (2016) Brain training: hype or hope? Neuropsychol Rehabil 26(5-6):639-644

van Mierlo ML, Schröder C, van Heugten CM, Post MW, de Kort PL, Visser-Meily JM (2014) The influence of psychological factors on health-related quality of life after stroke: a systematic review. Int J Stroke 9(3):341-348

Van Mierlo M, van Heugten C, Post M, de Kort P, Visser-Meily J (2015) Psychological factors determine depressive symptomatology after stroke. Arch Phys Med Rehabil 96(6):1064-1070

van Rijsbergen MW, Mark RE, de Kort PL, Sitskoorn MM (2014) Subjective cognitive complaints after stroke: a systematic review. J Stroke Cerebrovasc Dis 23(3):408-420 
van Rijsbergen MW, Mark RE, de Kort PL, Sitskoorn MM (2015) Prevalence and profile of poststroke subjective cognitive complaints. J Stroke Cerebrovasc Dis 24(8):1823-1831

Verbraak ME, Hoeksma AF, Lindeboom R, Kwa VIH (2012) Subtle problems in activities of daily living after a transient ischemic attack or an apparently fully recovered non-disabling stroke. $\mathrm{J}$ Stroke Cerebrovasc Dis 21:124-130

Visser-Keizer AC, Hogenkamp A, Westerhof-Evers HJ, Egberink IJ, Spikman JM (2015) Dutch multifactor fatigue scale: a new scale to measure the different aspects of fatigue after acquired brain injury. Arch Phys Med Rehabil 96(6):1056-1063

Wagle J, Fanrer L, Flekoy K, Bruun Willer T, Sandvik L, Fure B, Stensrod B, Engedal K (2011) Early post-stroke cognition in stroke rehabilitation patients predicts functional outcome at 13 months. Dement Geriatr Cogn Disord 31:379-387

Wessel MJ, Zimmerman M, Hummel FC (2015) Non-invasive brain stimulation: an intervenjtional tool for enhancing behavioral training after stroke. Front Hum Neurosci 9:265

West C, Bowen A, Hesketh A, Vail A (2008) Interventions for motor apraxia following stroke. Cochrane Database Syst Rev 2008(1):CD004132

Whyte EM, Mulsant BH (2002) Post stroke depression: epidemiology, pathophysiology, and biological treatment. Biol Psychiatry 52:253-264

Williams WH, Evans JJ (2003) Biopsychosocial approaches in neurorehabilitation. Special issue. Neuropsychol Rehabil 13(1-2):1-325

Wilson BA, Herbert CM, Shiel A (2003) Behavioral approaches in neuropsychological rehabilitation: Optimising rehabilitation procedures. Psychology Press, Hove

Wilson BA, Evans JJ, Gracey F, Bateman A (2009) Neuropsychological rehabilitation: theory, models, therapy and outcomes. Cambridge University Press, Cambridge

Wilson BA, Winegardner J, van Heugten CM, Ownsworth T (2017) Neuropsychological rehabilitation: the international handbook. Routledge Taylor \& Francis Group, Cambridge

Winstein CJ, Stein J, Arena R, Bates B et al (2016) Guidelines for adult stroke rehabilitation and recovery: a guideline for healthcare professionals from the American Heart Association/ American Stroke Association. Stroke 47(6):e98-e169

Wogensen E, Mala H, Mogensen J (2015) The effects of exercise on cognitive recovery after acquired brain injury in animal models: a systematic review. Neural Plast 2015:830871

Wu S, Kutlubaev Mansur A, Chun H-Y, Cowey E et al (2015) Interventions for post-stroke fatigue. Cochrane Database Syst Rev 2015(3):CD007030

Yeo S, Lian Z, Mao J, Yau W (2017) Effects of central nervous system drugs on recovery after stroke: a systematic review and meta-analysis of randomized controlled trials. Clin Drug Investig 37:901-928

Open Access This chapter is licensed under the terms of the Creative Commons AttributionNonCommercial-NoDerivatives 4.0 International License (http://creativecommons.org/ licenses/by-nc-nd/4.0/), which permits any noncommercial use, sharing, distribution and reproduction in any medium or format, as long as you give appropriate credit to the original author(s) and the source, provide a link to the Creative Commons license and indicate if you modified the licensed material. You do not have permission under this license to share adapted material derived from this chapter or parts of it.

The images or other third party material in this chapter are included in the chapter's Creative Commons license, unless indicated otherwise in a credit line to the material. If material is not included in the chapter's Creative Commons license and your intended use is not permitted by statutory regulation or exceeds the permitted use, you will need to obtain permission directly from the copyright holder. 